\title{
The Synthesis and Toxicological Characterization of Neurotoxic Chemical Agents Simulants
}

\author{
MIHAI SILVIU TUDOSIE ${ }^{1}$, CRISTINA ANCA SECARA*, CATALIN GABRIEL SMARANDACHE ${ }^{1}$, SIMONA BICHERU², \\ MIH AELA MURESAN ${ }^{3}$, BOGDAN SOCEA ${ }^{1}$, NICOLETA GRIGORIU33, CRISTINEL DUMITRU BADIU ${ }^{1}$, GABRIEL EPURE ${ }^{3}$, \\ ANA MARIA DASCALU ${ }^{1}$, CONSTANTIN DRAGHICI ${ }^{2,4}$ \\ ${ }^{1}$ Carol Davila University of Medicine and Pharmacy of Bucharest, 37 Dionisie Lupu, 020021, Bucharest, Romania \\ ${ }^{2}$ Medical-Military Scientific Research Center of Bucharest, 3-5 Institutul Medico - Militar Str., 010919, Bucharest, Romania \\ ${ }^{3}$ Scientific Research Center for CBRN Defense and Ecology (SRCCBRNDE) of Bucharest, 225 Oltenitei, 041309, Bucharest, \\ Romania \\ ${ }^{4}$ Organic Chemistry Institute of Bucharest, 202B Splaiul Independentei, 060021, Bucharest, Romania
}

\begin{abstract}
Neurotoxic warfare chemical agents (CWA/NA) induce major toxicological effects to the affected personnel. Their increased toxicity justifies the necessity of developing analytical methods for diagnosis and specific medical counter measures. CWA/NA are extremely toxic agents which are subjectto international regulations (The Geneva Protocol regarding the prohibition of chemical weapons). Taking into account the ban on human experimenting due to high toxicity, simulators of neurotoxic chemical agents are being used in laboratories. These are analogue chemical compounds which possess the same relevant physical, chemical and pharmacodynamical properties of the corresponding agents, but with lower intrinsical toxicity. The synthesis and toxicological characterization of these simulators of neurotoxic chemical agents allow the laboratory research of these extremely toxic compounds and the unfolding of risk-free antidote studies. This paper proposes the synthesis and toxicological testing of chemical compounds which simulate sarin (4nitrophenyl isopropyl methylphosphonate - NIMP) and VX (4-nitrophenyl ethyl methylphosphonate - NEMP).
\end{abstract}

Keywords: NIMP, NEMP, neurotoxic chemical agents, acute toxicity, acetylcholinesterase (AchE)

High-risk neurotoxic chemical agents (sarin, soman, tabun, VX) are extremely toxic compounds which have structures of phosphoric acid esters [1-8]. Due to their extremely high toxicity, they were registered on the list of substances which must be destroyed according to the international regulations (Convention on the Prohibition of the Development, Production and Stockpiling of Chemical Weapons). Their production, stockpiling and use are monitored by international organizations (Organization for the Prohibition of Chemical Weapons - OPCW) [9-13]. Neurotoxic chemical agents have the property of irreversibly inhibiting the erythrocytary acetylcholinesterase (AChE) [14-18]. The coupling reaction of the organophosphoric compounds at the level of the active situs of the enzyme is represented in fig.1, 2.

The AChE inhibition leads to the acummulation of acetycholine (ACh) in the synaptic cleft and to the hyperstimulation of muscarinic and nicotinic receptors [21, 22]. The clinical signs of mild intoxication are pupil constriction, sweating, muscle fasciculations, bradycardia and a decrease in blood pressure. Athigher concentrations of the toxic agent, convulsions occur and, eventually, death through respiratory insufficiency due to the paralysis of respiratory centers. Cholinesterase inhibiting neurotoxic organophosphoric compounds possess, in their molecule,

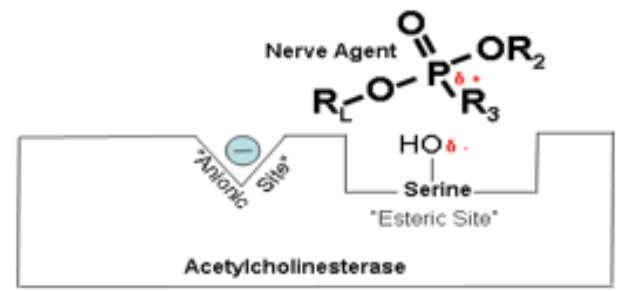

Fig. 1. The coupling mechanism of the organophosphoric compound at the level of the active situs of AChE (diagram modified from [19]) two organic groups, identical or different, and and active group, inorganic or organic, bound to a pentavalent phosphor atom. The central pentavalent phosphor atom can be bound to an oxygen or sulphur atom (phosphates, phosphonates, tionphosphates, tionphosphonates). In specialty scientific literature, potential simulators were presented for each class of warfare chemical neurotoxic agents [23-26]. The chemical compounds that were identified as possible simulators of neurotoxic agents, necessary in research activity regarding the optimization of specific treatment in the intoxication with neurotoxic organophosphoric compounds, are the non-volatile compunds: 4-nitrophenyl isopropylic methylphosphonate (NIMP) for sarin and 4-nitrophenyl ethyl methylphosphonate (NEMP) for VX. These maintain, within their molecule, the active group $\mathrm{F}-\mathrm{P}=0$ which is responsible for the toxicological properties. In fig. 3, the chemical structure of neurotoxic agents and their corresponding simulators are being shown $[4,6,14,17,24]$.

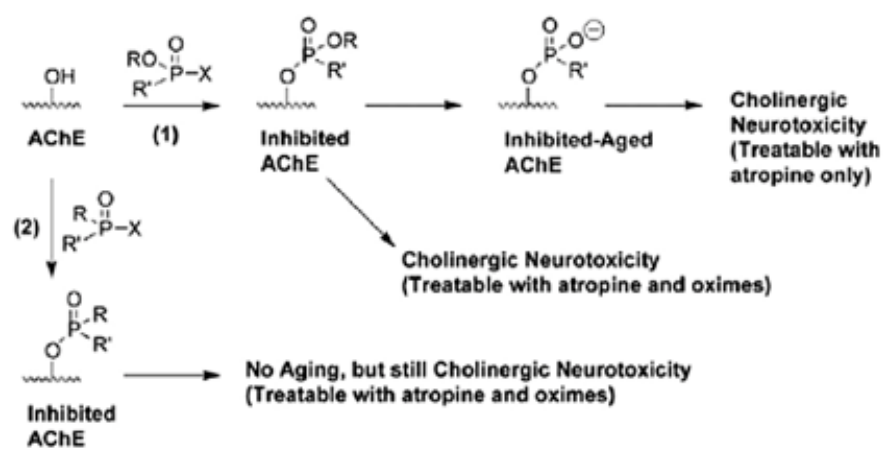

Fig. 2. Interaction between AchE and organophosphoric compound (after [20])

* email: csarbulescu@yahoo.com, Phone: +40722528230

REV.CHIM.(Bucharest) $70 \diamond$ No. $11 \bullet 2019$ http://www.revistadechimie.ro 


Isopropyl phosphonofluoridate (Sarin)

The laboratory use of neurotoxic chemical agents is restricted, as they are extremely toxic substances. The chemical compounds identified as simulators of these neurotoxic agents in studies regarding the optimization of specific treatment in the intoxication with neurotoxic organophosphoric compounds are two non-volatile compounds: a simulator of tabun, 4-nitrophenyl ethyl methylphosphonate (NEMP, a simulator for VX), and 4nitrophenyl isopropyl methylphosphonate (NIMP) $[23,24]$. Their synthesis was performed in the Chemical Analyses and Special Syntheses Laboratory, Section 1, of C.C.S.A.C.B.R.N.E.

\section{General objectives}

-the reduction in the risks the personnel which executes testing procedures for high-toxicity chemical compounds is subject to, through the synthesis and use of simulators of neurotoxic chemical agents in the laboratory.

-the optimization of medical countermeasures in the case of exposure to neurotoxic chemical agents through the extension of studies of antidotism with the condition of simulator use

\section{Specific objectives}

- The synthesis and chemical characterization of NIMP and NEMP simulators with purity of $\geq 90 \%$

- The evaluation of the acute toxicity of NIMP and NEMP compared to their corresponding neurotoxic chemical agents

- The evaluation of their AChE inhibition properties compared to their analogues.

\section{Experimental part}

\section{Materials and method}

Methods of synthesis for simulators of neurotoxic agents

Simulators are mostly esters (mono esters, symmetrical or asymmetrical diesters) of alkyl phosphonic acids, being obtained through a synthesis reaction which involves compounds called precursors. The esterification reactions are performed in the presence of a tertiary amine which has the role of blocking the formed hydrochloric acid and favoring the binding of the ester. The shifting of the equilibrium towards ester forming was performed through the use of an excess components (alcohol) and the unfolding of the reaction under inert gas pressure. The synthesis reactions were performed in two stages, at room temperature, the mass temperature being maintained within certain limits to avoid the decomposure of the product [5]. The syntheses were performed using methylphosphonic dichloride as a precursor, as it is a rather reactive substance and, thus, the esterification reaction can unfold without a catalyst. Using two different alcohols for esterification: ethanol and 2-propanol, in an alkylphosphonic dichloride/alcohol molar ratio of $1 / 2$, the nitrophenyl ester omologues identified as simulators of neurotoxic chemical agents were obtained. The final reaction product is an oily liquid which is homogenous and of brown color.

The synthesis reaction of the two non-volatile compounds, NIMP and NEMP, identified as possible simulators of neurotoxic agents, are shown in fig. 5 and fig. 6 (after [27]):

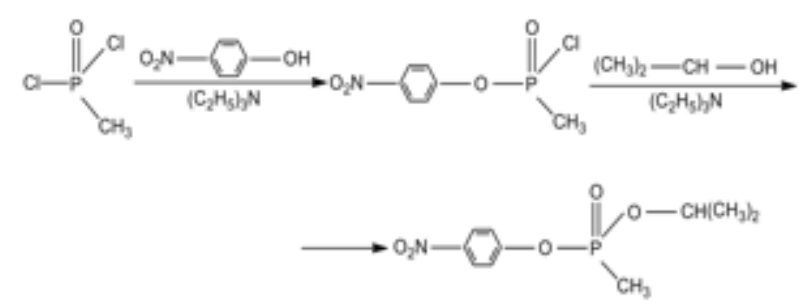

Fig. 5. Synthesis reaction of NIMP

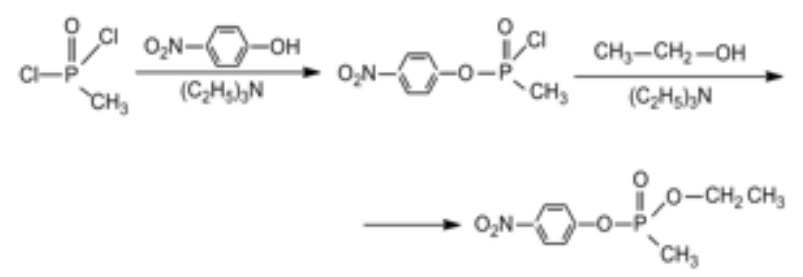

Fig. 6. Synthesis reaction of NEMP

Identification and characterization of simulator compounds were performed through gas-chromatography coupled with mass spectrometry (GC/MS). The chromatographic analysis performed with GC/MS DSQ II Thermo Electron Corporation confirmed the structure of the analysed compounds.

The GC/MS mass spectrums of the two compounds, NIMP and NEMP, are shown in fig. 7 ( $a$ and $b$ ).

\section{RMN Characterization}

The purity of NIMP and NEMP compounds, determined with RMN $1 \mathrm{H}$, was of $90 \%$ and $94 \%$.

\section{NIMP - Hydrogen spectrum}

Spectrum ${ }^{1} \mathrm{H}-\mathrm{RMN}\left(\mathrm{CDCl}_{3}, \delta \mathrm{ppm}, \mathrm{i}_{\mathrm{Hz}}\right): 8.14(\mathrm{~d}, 9.3,2 \mathrm{H}$, $\mathrm{H}-2, \mathrm{H}-6) ; 7.31(\mathrm{dd}, 1.4,9.3) ; 4.76(\mathrm{~m}, 1 \mathrm{H}, \mathrm{H}-9) ; 1.60(\mathrm{~d}, 17.6$, $3 \mathrm{H}, \mathrm{H}-8) ; 1.28(\mathrm{~d}, 6.3,3 \mathrm{H}, \mathrm{H}-10) ; 1.19\left(\mathrm{~d}, 6.3,3 \mathrm{H}, \mathrm{H}-10^{\prime}\right) \mathrm{s}=$ singlet, $d=$ doublet, $t=$ triplet, $s x=$ sextet,$m=$ multiplet

In the $\mathrm{H}$ spectrum, the para substitution through the 2 $A B$ type systems for the 4 protons can be observed, paired as 2 equivalents, the most deshielded $H_{2}, H_{6}$ (higher $\delta$ ) from 8.14 dublet with a coupling constant of $9.3 \mathrm{~Hz}$, and the most shielded (orto in regards to oxygen) $\mathrm{H}_{3}, \mathrm{H}_{5}$ at 7.31 with the same coupling constant. The methyl group bound to a $P$ is a doublet with $v=18.0 \mathrm{ppm}$ (coupled with phosphorus) and the isopropyl rest is confirmed by $\mathrm{H}-9$ 


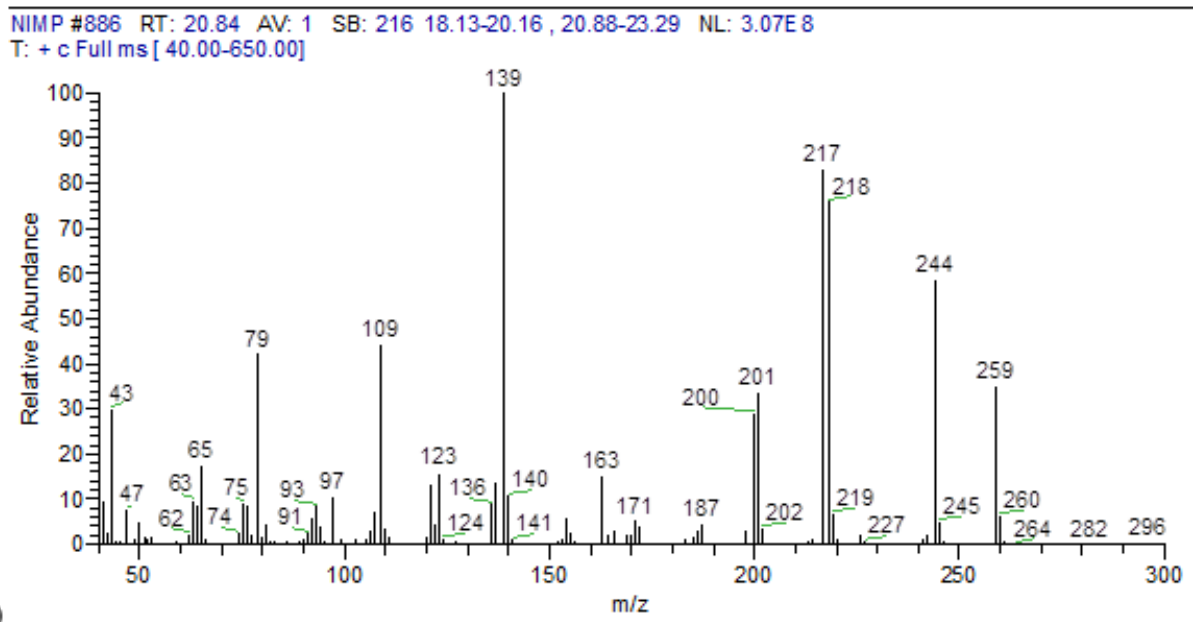

a)

C:Xcaliburldata12014 IDIVER SE WNE M P

$09.04 .201412: 34: 21$

NEMP \#871 RT: 20.53 AV: 1 SB: 128 18.76-20.09, 20.57-21.85 NL: $3.59 E 7$

$\mathrm{T}:+\mathrm{c}$ Full ms [ 40.00-650.00]

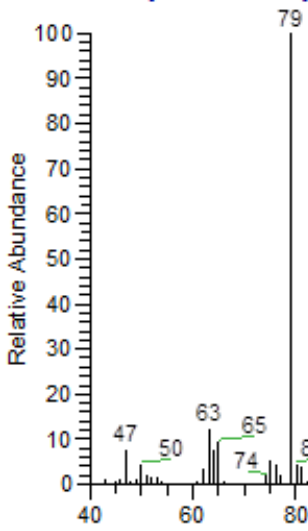

b)

which is a multiplet at $\delta=1.19 \mathrm{ppm}$ (which comes from a heptet) coupled with the two methyls and, also, a coupling with phosphorus appears, theoretically $7 \times 2=14$ lines. The
Fig. 7. Mass spectrums (GC-EI-MS) for NIMP (a) and NEMP (b). Capillary column

TR5 MS/5\% Phenyl 95\% dimethylpolysiloxan, $30 \mathrm{mx}$ $0.25 \mathrm{~mm} \times 0.25 \mu \mathrm{m}$; helium carrier gas $1.5 \mathrm{ml} / \mathrm{min}$. Injector temperature $250^{\circ} \mathrm{C}$, electron energy $70 \mathrm{eV}$; mass domain $40-650 \mathrm{~m} / \mathrm{z}$

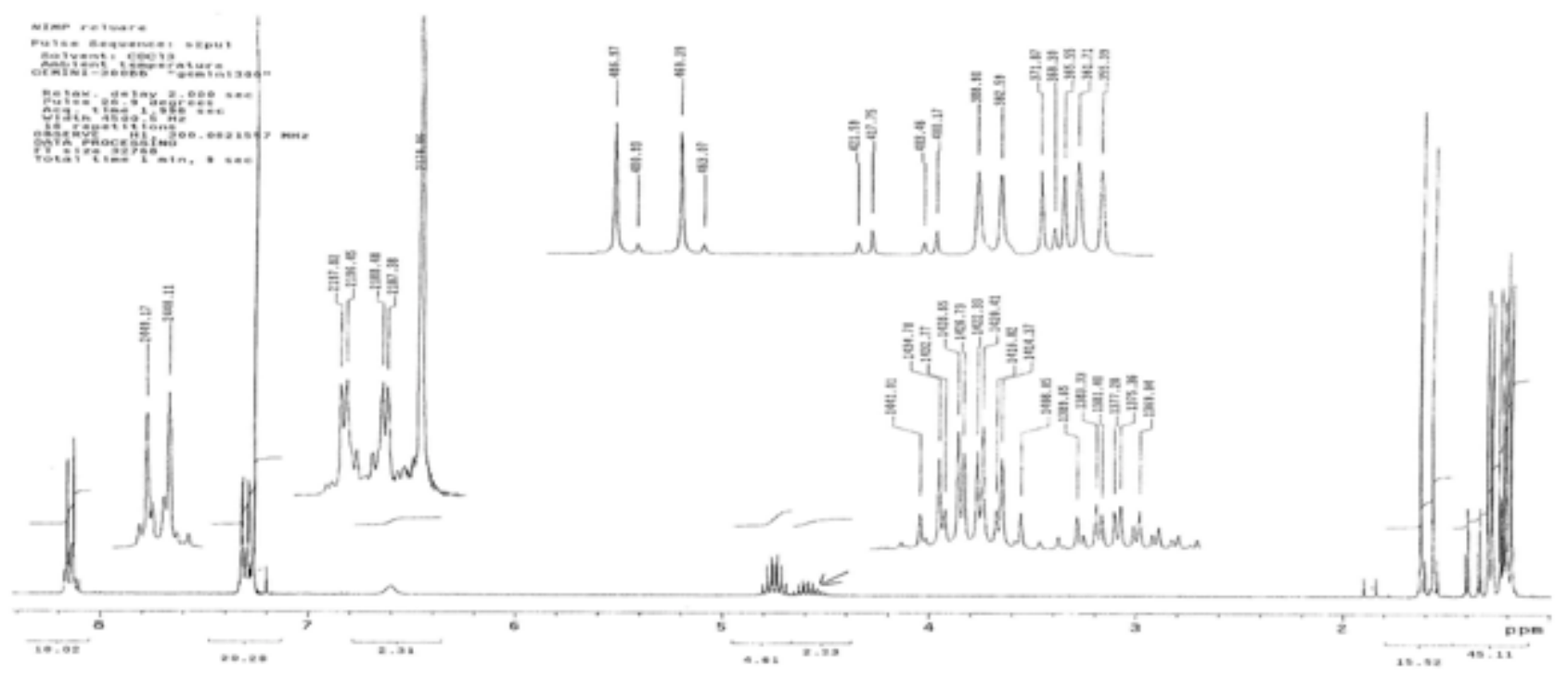

Fig. 8. NIMP - Hydrogen spectrum 


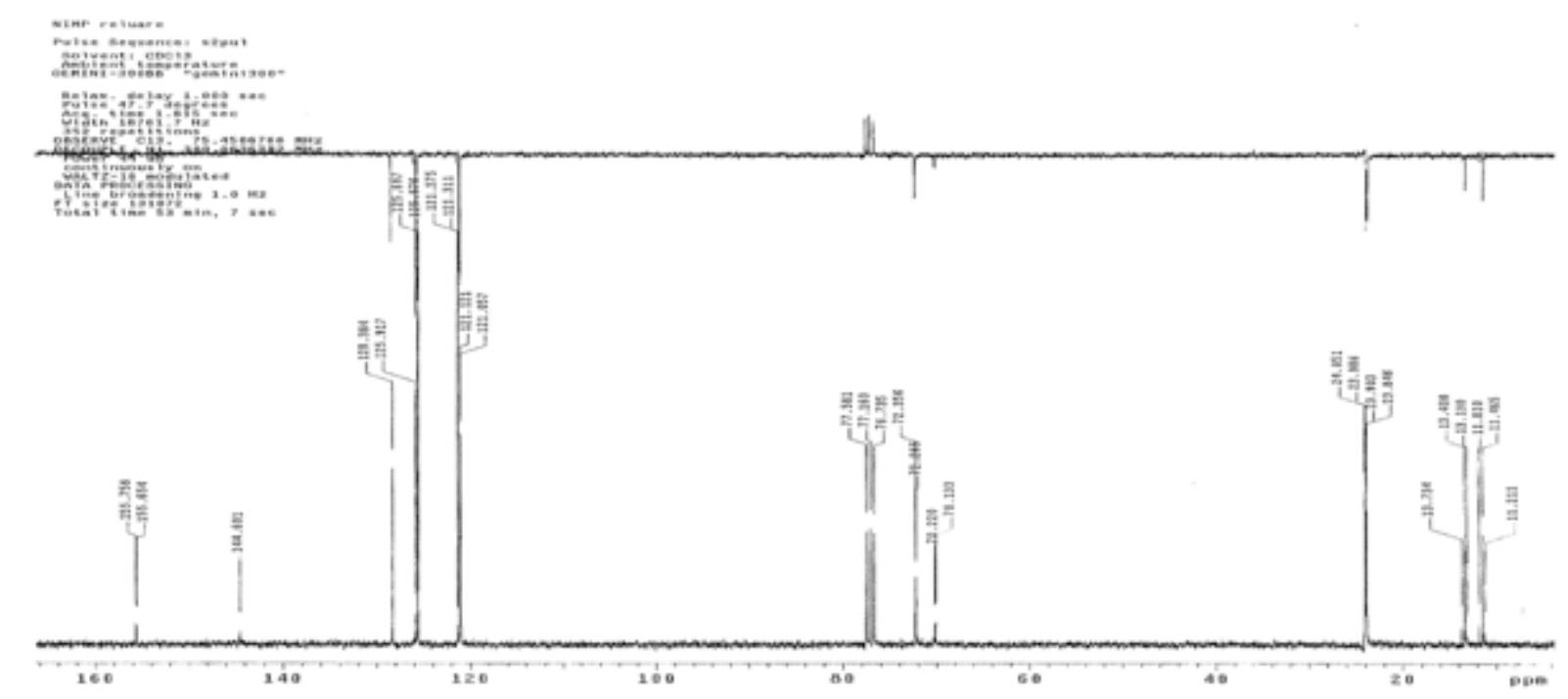

Fig. 9. NIMP - Carbon spectrum

\section{NIMP-Carbon spectrum}

${ }^{13} \mathrm{C}-\mathrm{RMN}$ spectrum $\left(\mathrm{CDCl}_{3}, \delta \mathrm{ppm}\right): 155.71(\mathrm{~d}, 7.7, \mathrm{C}-4)$; 144.60(C-1); 125.62(d, 9.1, C-2, C-6); 121.12(d, 5.0, C-3, C5); $72.36(d, 6.8, C-9) ; 23.98(d, C-8) ; 13.13(C-10) ; 11.81(C-$ $\left.10^{\prime}\right)$

The carbon spectrum shows the aromatic nucleus which is para substituted and the coupling of carbon atoms with phosphorus. The most deshielded carbon atom is $\mathrm{C}-4$ at ä $=155.71 \mathrm{ppm}$ geminal with oxygen, after which is C-1 geminal with the nitro group at $\delta=144.60 \mathrm{ppm}$. The tertiary equivalent carbon atoms $C-2$ and $C-6$ appear at $\delta=125.62$ ppm and C-3, C-5, also equivalents, appear at $\delta=121.12$ $\mathrm{ppm}$. The remaining alkyl appear as $\mathrm{CH}$ (isopropyl) at $\delta=72.36 \mathrm{ppm}, \mathrm{CH}_{3}-\mathrm{P}$ group at $\delta=23.98 \mathrm{ppm}$ and the two methyl groups of isopropyl at 13.13 and 11.81ppm (Fig. 9).
4-Nitrophenyl 2-ethylmethylphosphonate - NEMP: (simulator of VX)

RMN characterization

NEMP - Hydrogen spectrum ${ }^{1} \mathrm{H}-\mathrm{RMN}(\mathrm{CDCl}, \delta \mathrm{ppm}, v$ $\mathrm{Hz}): 8.17(\mathrm{~d}, 9.3,2 \mathrm{H}, \mathrm{H}-2, \mathrm{H}-6) ; 7.33(\mathrm{dd}, 1.1,9.3,2 \mathrm{H}, \mathrm{H}-3, \mathrm{H}-$ 5); $4.15(\mathrm{~m}, 2 \mathrm{H}, \mathrm{H}-9) ; 1.63(\mathrm{~d}, 18.0,3 \mathrm{H}, \mathrm{H}-8) ; 1.27(\mathrm{t}, 7.1$, $3 \mathrm{H}, \mathrm{H}-10)$ Para substitution shows for the 4 aromatic protons two $A B$ systems with a coupling of $9.3 \mathrm{~Hz}$. H-2 and $\mathrm{H}-6$ equivalents protons appear at $\delta=8.17 \mathrm{ppm}$, more deshielded due to the $\mathrm{NO}_{2}$ group, and the most shielded are $\mathrm{H}-3, \mathrm{H}-5$ (due to the oxygen) at $\delta=7.33 \mathrm{ppm}$. The remaining ethyl is confirmed by the multiplet at $4.15 \mathrm{ppm}$ (Theoretically a dedoubled coupling quartet with the phosphorus), for the methylen group $\mathrm{H}-9$, and the ethyl group through the triplet at $1.27 \mathrm{ppm}$ with the coupling constant of $7.1 \mathrm{~Hz}$. The methyl group bound to phosphorus is confirmed by the doublet of $18.0 \mathrm{~Hz}$ at $1.63 \mathrm{ppm}$, due to coupling with phosphorus (fig. 10)

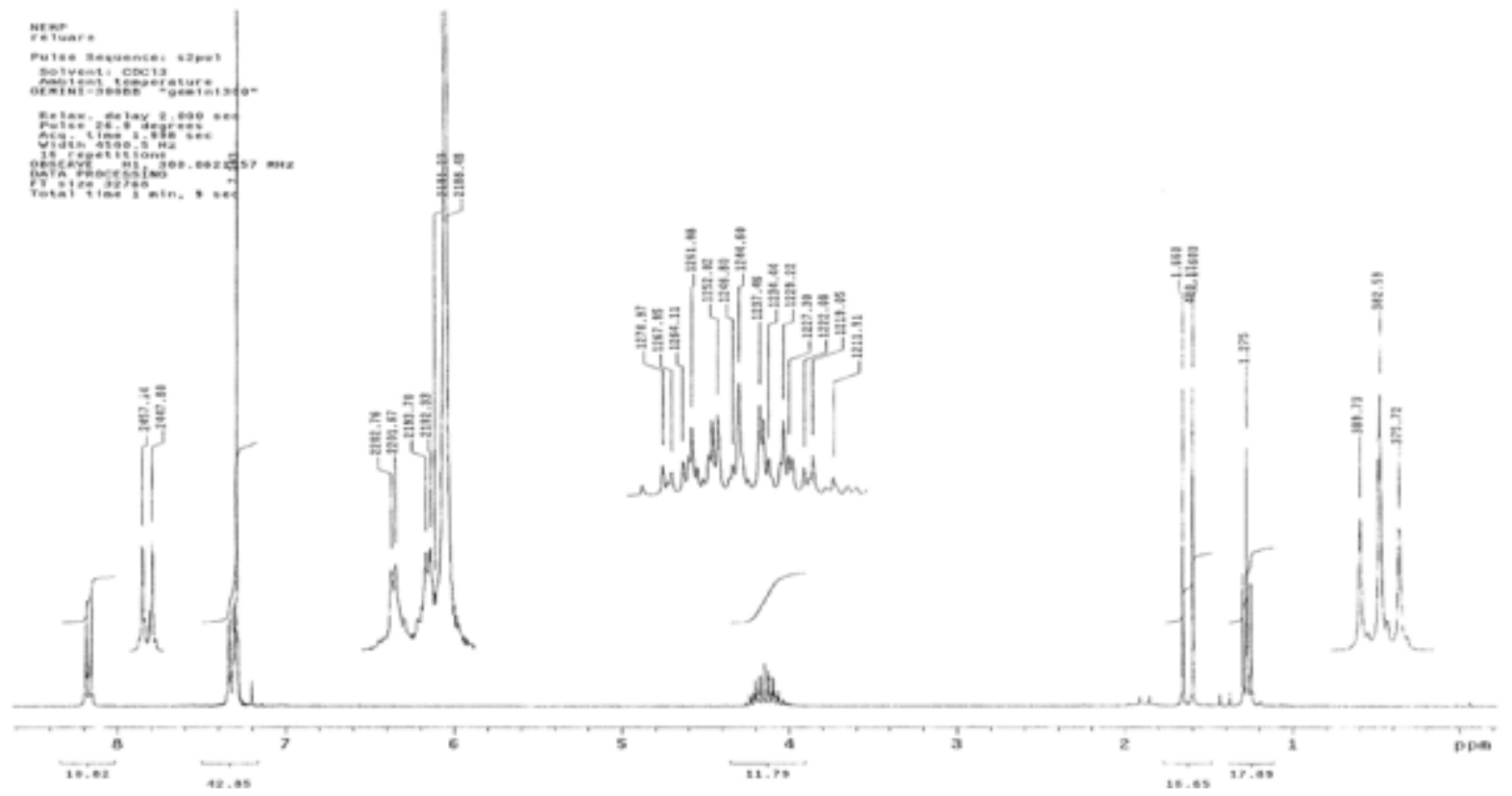

Fig. 10. NEMP - Hydrogen spectrum 


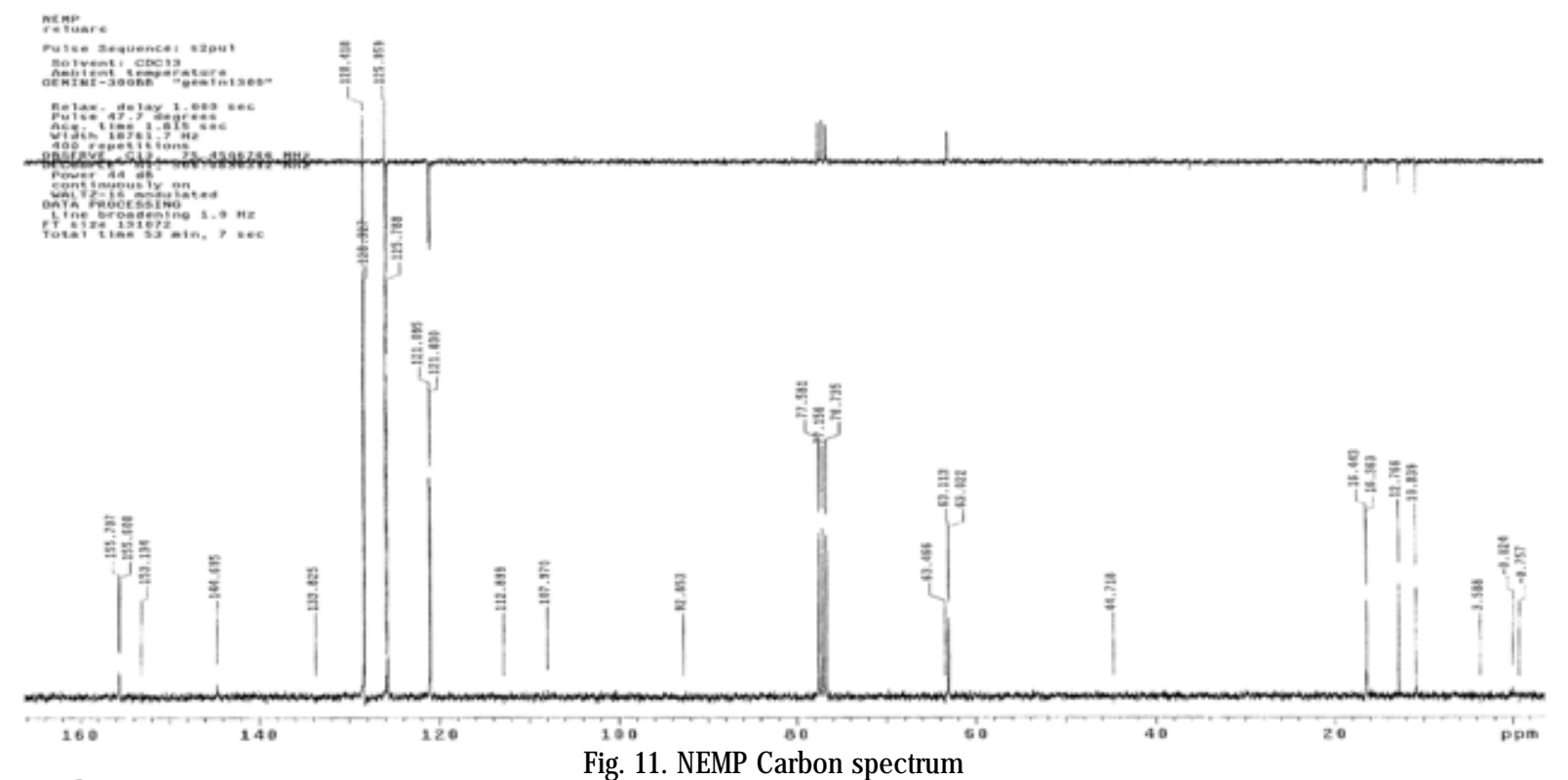

NEMP- Carbon spectrum

Fig. 11. NEMP Carbon spectrum

${ }^{13} \mathrm{C}$-RMN spectrum ( $\left.\mathrm{CDCl}_{3}, \delta \mathrm{ppm}\right): 155.65(\mathrm{~d}, 8.0, \mathrm{C}-4)$; 144.70(C-1); 125.82(d, 12.8, C2-C6); $121.70(4.9$, C3-C5); 63.11(C-9); 16.40(d, 6.0, C-8); 12.70(C-10) (fig. 11).

The pharmacotoxicological characterization of the tested compounds

The in vivo testing of the acute toxicity of the two compunds, NIMP and NEMP $\left(D L_{50}\right)$

Tested substances:

-4 nitrophenyl isopropyl methylphosphonate (NIMP) synthethised and characterized in the Chemical Analyses and Special Syntheses Laboratory, Section 1, of C.C.S.A.C.B.R.N.E

-4 nitrophenyl ethyl methylphosphonate (NEMP) synthethised and characterized in the Chemical Analyses and Special Syntheses Laboratory, Section 1, of C.C.S.A.C.B.R.N.E.

\section{The preparation of solutions:}

-NIMP: $0,033 \mathrm{~mL}$ are dissolved in $5 \mathrm{~mL}$ DMSO. From this solution, $1 \mathrm{ml}$ is dissolved in $19 \mathrm{ml}$ distilled water in a graded $20 \mathrm{ml}$ bottle leading to a working solution of $0.38 \mathrm{mg} / \mathrm{mL}$. -NEMP: $0.040 \mathrm{~mL}$ are dissolved in $5 \mathrm{~mL}$ DMSO. From this solution, $1 \mathrm{~mL}$ is dissolved in $19 \mathrm{~mL}$ distilled water in a graded $20 \mathrm{~mL}$ bottle leading to a working solution of 0.40 $\mathrm{mg} / \mathrm{mL}$.

\section{Biological material}

10 groups of 10 animals were used in the experiment (male Wistar rats) weighing on average $200-250 \mathrm{~g}$, fed a daily constant portion of standard food, with free access to water, kept in optimal temperature, humidity, lighting and away from contact with pesticides.

\section{Experimental protocol}

The following pharmacodynamic parameters were determined: $\mathrm{DL}_{50}$ and the inhibition degree of erythrocitary $\mathrm{AChE}$ and plasmatic BuChE for the two selected surrogate compounds, as well as the protection index after the administration of a fixed antidote ATOX combination ATOX. Each intoxicated and treated group was considered a control group for itself. The NIMP and NEMP doses administered experimentally were calculated in geometrical progression utilizing the literature references.

Group 1 - This group was intoxicated with a dose of NIMP of $0.59 \mathrm{mg} / \mathrm{kg}$ i.p. coded as the high dose. The mortality and intoxication signs were examined. Every 60

minutes from intoxication, $0.2 \mathrm{~mL}$ of blood were sampled from the same animals on an anticoagulant to measure the inhibition of erythrocitary Acetycholinesterase inhibition.

Group 2 - This group was intoxicated with a dose of NIMP of $0.47 \mathrm{mg} / \mathrm{kg}$ i.p. coded as the moderate dose. The mortality and intoxication signs were examined. Every 60 minutes from intoxication, $0.2 \mathrm{~mL}$ of blood were sampled from the same animals on an anticoagulant to measure the inhibition of erythrocitary Acetycholinesterase inhibition.

Group 3 - was intoxicated with a dose of NIMP of 0.38 $\mathrm{mg} / \mathrm{kg}$ i.p. coded as the low dose. The mortality and intoxication signs were examined. Every 60 minutes from intoxication, $0.2 \mathrm{ml}$ of blood were sampled from the same animals on an anticoagulant to measure the inhibition of erythrocitary Acetycholinesterase inhibition.

Group 4 - was intoxicated with a dose of NEMP of 0.64 $\mathrm{mg} / \mathrm{kg}$ i.p. coded as the high dose. The mortality and intoxication signs were examined. Every 60 minutes from intoxication, $0.2 \mathrm{~mL}$ of blood were sampled from the same animals on an anticoagulant to measure the inhibition of erythrocitary Acetycholinesterase inhibition.

Group 5 - was intoxicated with a dose of NEMP of 0.51 $\mathrm{mg} / \mathrm{kg}$ i.p. coded as the moderate dose. The mortality and intoxication signs were examined. Every 60 minutes from intoxication, $0.2 \mathrm{~mL}$ of blood were sampled from the same animals on an anticoagulant to measure the inhibition of erythrocitary Acetycholinesterase inhibition.

Group $6-0.2 \mathrm{~mL}$ of blood was sampled through cardiac punction on an anticoagulant for the spectrophotometric measuring of normal values of erythrocitary acetylcholinesterase; Eventually, they were intoxicated with a dose of NEMP of $0.40 \mathrm{mg} / \mathrm{kg}$ i.p. coded as the low dose. The mortality and intoxication signs were examined. Every 60 minutes from intoxication, $0.2 \mathrm{~mL}$ of blood were sampled from the same animals on an anticoagulant to measure the inhibition of erythrocitary Acetycholinesterase inhibition.

Group 7 (control group) was administered $1.5 \mathrm{~mL}$ of physiological serum and $\mathrm{s} 0.2 \mathrm{~mL}$ of blood was sampled through cardiac punction on an anticoagulant for the spectrophotometric measuring of normal values of erythrocitary acetylcholinesterase;

The method of measuring acetylcholinesterase levels: was performed using the AChE Elisa rat kit for determining acetylcholinesterase in rats. Initially, at the time considered 
T0, $1 \mathrm{~mL}$ of blood was sampled on citrate to determined normal values of acetylcholinesterase through the Elisa rat kit micromethod. The blood samples were processed according to the working protocol of AchE Elisa rat kit micromethod. For the statistical analysis, the T Student test, ANOVA and TURKEY were used.

\section{Results and discussions}

Determining the $D L_{50}$ interval for the NIMPcompound

The steps for analysing the results corresponding to the determining of the $\mathrm{DL}_{50}$ interval for the NIMP compound are shown in table 1 and fig. 12.

The square value of the correlation coefficient is 0,991 , and the logarhythm values of the doses administered to groups 1,2,3, being approximately on the regression line, show the experimental results are correct and that the $\mathrm{DL}$ interval for the NIMP compounds is between $0.32-0.59$ mg/kg i.p. DL resulted from calculation (represented by the value of $x$ if, in the regression line, the value of $y$ is 5), is $0.45 \pm 0.002 \mathrm{mg} / \mathrm{kg}$ i.p

Determining the $D L$ interval for the NEMP compound

The steps for analysing the results corresponding to the determining of the $\mathrm{DL}_{50}$ interval for the NEMP compound are shown in table 2 and fig. 13.

Doses of NIMP determine an inhibition of AchE of $95.72 \%, 87.38 \%$ and $53.15 \%$ (fig. 14).

\begin{tabular}{|c|c|c|c|c|c|}
\hline No. & Gr. no. & NIMP dose mg/kg & $\begin{array}{c}\text { Dose } \\
\text { logarhythm }\end{array}$ & $\begin{array}{c}\text { Percentile } \\
\text { mortality probit }\end{array}$ & $\begin{array}{c}\text { Percentile } \\
\text { mortality }\end{array}$ \\
\hline 1 & Gr. 1 & 0.59 & -0.23 & 5.81 & $80 \%$ \\
\hline 2 & Gr. 2 & 0.47 & -0.33 & 4.86 & $60 \%$ \\
\hline 3 & Gr. 3 & 0.32 & -0.42 & 4.24 & $20 \%$ \\
\hline
\end{tabular}

Table 1

STEPS OF STATISTICAL ANALYSIS AND OF CALCULATING OF DL 50 INTERVAL

Legend: $X$ axis - logarhythm values of doses administered to the 3 groups in the experiment; $Y$ axis - values of corresponding probits of percentile mortality for each group

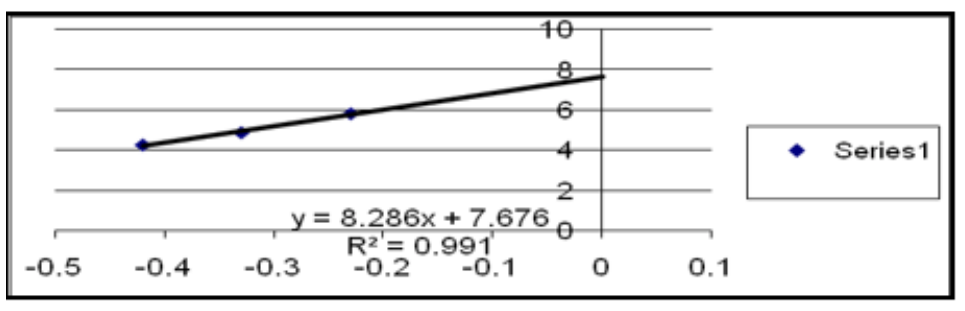

Fig. 12. Calculating $\mathrm{DL}_{50}$ Representation of the regression line and of correlation coefficient

\begin{tabular}{|c|c|c|c|c|c|}
\hline No. & Gr. no. & NEMP dose mg/kg & $\begin{array}{c}\text { Dose } \\
\text { logarhythm }\end{array}$ & $\begin{array}{c}\text { Percentile } \\
\text { mortality probit }\end{array}$ & $\begin{array}{c}\text { Percentile } \\
\text { mortality }\end{array}$ \\
\hline 1 & Gr. 4 & 0.64 & -0.19 & 5.94 & $70 \%$ \\
\hline 2 & Gr.5 & 0.51 & -0.29 & 5 & $50 \%$ \\
\hline 3 & Gr. 6 & 0.4 & -0.39 & 4.16 & $10 \%$ \\
\hline
\end{tabular}

Table 2

STEPS OF STATISTICAL ANALYSIS AND OF CALCULATING OF DL 50 INTERVAL

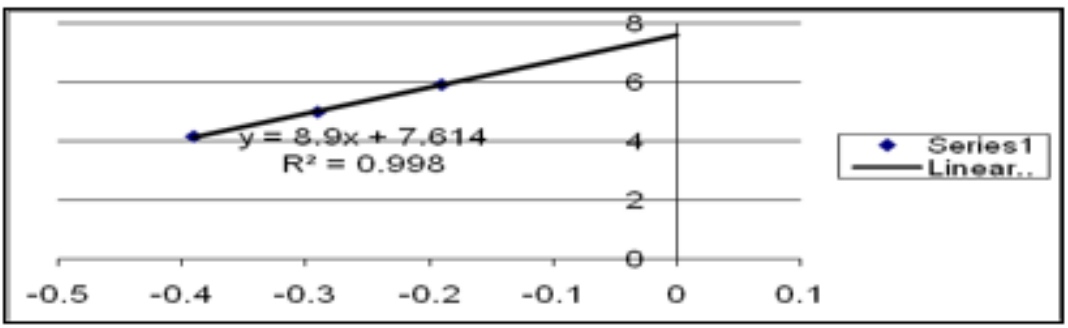

Fig. 13. Representation of the regression line and of correlation coefficient

Legend: $X$ axis- logarhythm values of doses administered to the 3 groups in the experiment;

$Y$ axis - values of corresponding probits of percentile mortality for each group;

The square value of the correlation coefficient is 0,998 , and the logarhythm values of the doses administered to groups 4,5,6, being approximately on the regression line, show the experimental results are correct and that the DL interval for the NEMP compounds is between $0.4-0.64$ $\mathrm{mg} / \mathrm{kg}$ i.p. and DL 50 (represented by the value of $x$ if, in the regression line, the value of $\mathrm{y}$ is 5 ) is $0.51 \pm 0.003 \mathrm{mg} /$ kg i.p.

Table 3

THE EVALUATION OF ACHE INHIBITION ACTIVITY FOR NIMP

\begin{tabular}{|c|c|c|c|c|c|c|}
\hline No. & Group & $\begin{array}{l}\text { Mean value of } \\
\text { AchE }(\mathrm{U} / \mathrm{L}) \\
\text { before } \\
\text { intoxication }\end{array}$ & $\begin{array}{l}\text { Dose of NIMP } \\
(\mathrm{mg} / \mathrm{kg}) \\
\text { administered i.p }\end{array}$ & $\begin{array}{l}\text { Mean value of } \\
\text { AChE activity } \\
\text { (mU/L) } 60 \text { minutes } \\
\text { from intoxication }\end{array}$ & $\begin{array}{l}\text { P probability } \\
\text { associated with } T \\
\text { Student test }\end{array}$ & Observations \\
\hline 1 & Gr. 1 & & 0.59 & 0.19 & 0.003 & \multirow{3}{*}{$\begin{array}{l}\mathrm{P}<0,05 \text { shows the initial } \\
\text { mean values of } \mathrm{Ach} E \\
\text { differ in a statistically } \\
\text { significant way from } \\
\text { those after intoxication }\end{array}$} \\
\hline 2 & Gr. 2 & & 0.47 & 0.56 & 0.004 & \\
\hline 3 & Gr. 3 & & 0.31 & 2.36 & 0.005 & \\
\hline 4 & Gr. 7 & 4.44 & - & - & & \\
\hline
\end{tabular}


NIMP AChE inhibition versus control

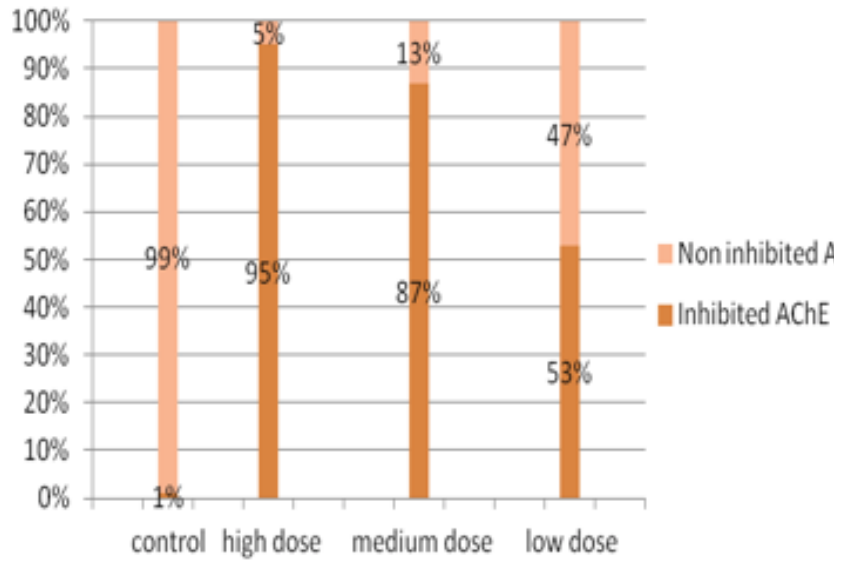

Fig. 14. AchE inhibition determined by NIMP
NEMP AChE inhibition versus control

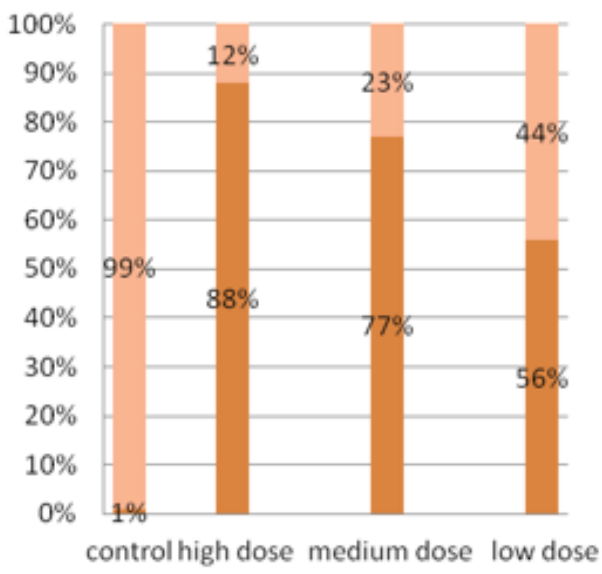

Fig.15. AChE inhibition determined by NEMP

Table 4

THE EVALUATION OF ACHE INHIBITION ACTIVITY FOR NIMP

\begin{tabular}{|c|c|c|c|c|c|c|}
\hline No. & Group & $\begin{array}{l}\text { Mean value of } \\
\text { AchE }(\mathrm{U} / \mathrm{L}) \\
\text { before } \\
\text { intoxication }\end{array}$ & $\begin{array}{l}\text { Dose of NEMP } \\
(\mathrm{mg} / \mathrm{kg}) \\
\text { administered i.p. }\end{array}$ & $\begin{array}{l}\text { Mean value of } \mathrm{Ach} \\
\text { activity }(\mathrm{mU} / \mathrm{L}) 60 \\
\text { minutes from } \\
\text { intoxication }\end{array}$ & $\begin{array}{l}\text { P probability } \\
\text { associated with } \\
\text { T Student test }\end{array}$ & Observations \\
\hline 1 & Group 4 & & 0.64 & 0.5 & 0.003 & \multirow{3}{*}{$\begin{array}{l}\mathrm{P}<0,05 \text { shows the } \\
\text { initial mean values of } \\
\text { AchE differ in a } \\
\text { statistically significant } \\
\text { way from those after } \\
\text { intoxication }\end{array}$} \\
\hline 2 & Group 5 & & 0.51 & 0.98 & 0.004 & \\
\hline 3 & Group 6 & & 0.40 & 2.46 & 0.005 & \\
\hline 4 & Group 7 & 4.44 & - & - & - & \\
\hline
\end{tabular}

Doses of administered NEMP determine an AChE inhibition of $88.73 \%, 77.92$ and $55.9 \%$ (fig. 15).

Statistical Anova and Turkey analyses of the experimental results complete the aspects shown above, revealing statistically significant differences $(p<0,05)$ between mean values of $A C h E$ inhibition, which were determined by the administered doses of the two studied compounds.

NIMP
ache lot
14.20 normal
$23.60 \mathrm{normal}$
$33.30 \mathrm{normal}$
45.30 normal
54.80 normal
60.20 high dose
70.18 high dose
80.63 moderate dose
90.68 moderate dose
100.40 moderate dose
110.53 moderate dose

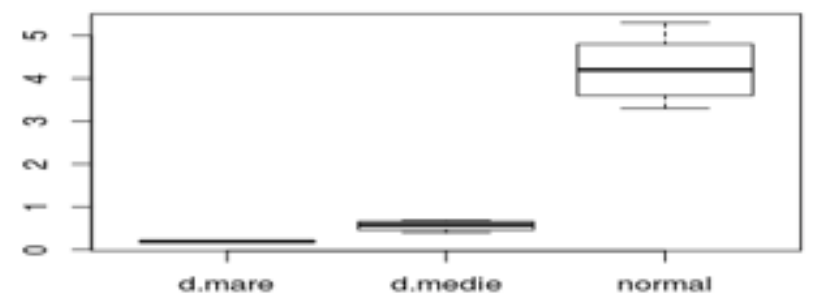

Tukey multiple comparisons of means $95 \%$ family-wise confidence level

diff Iwr upr $p$ adi

m. dose-h. dose $0.37-1.0881 .8280 .7562$

normal-h. dose $4.05 \quad 2.6415 .4590 .0001$

normal-m. dose $3.68 \quad 2.5504 .8100 .0000$

NEMP
ache lot
14.20 normal
23.60 normal
$33.30 \mathrm{normal}$
45.30 normal
54.80 normal
65.30 normal
70.53 high dose
80.67 high dose
90.32 high dose
100.74 moderate dose
110.94 moderate dose
120.90 moderate dose
131.34 moderate dose
141.10 moderate dose

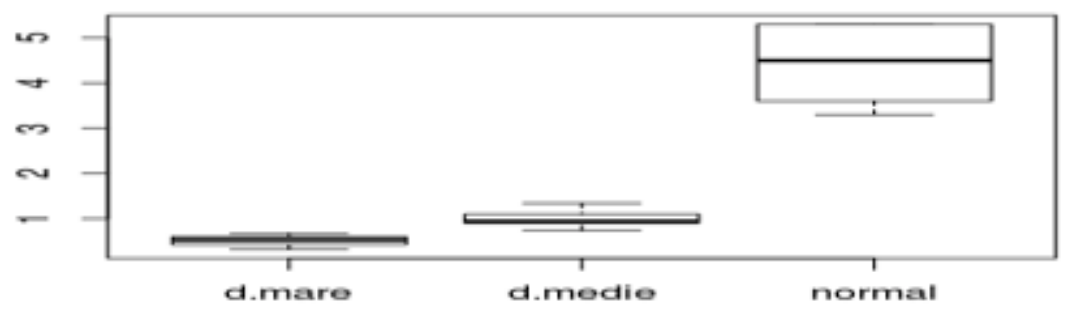


Tukey multiple comparisons of means 95\% family-wise confidence level

$$
\text { diff Iwr upr } p \text { adj }
$$

m. dose - h. dose $0.4973-0.68271 .6770 .5118$

normal-h. dose 3.91002 .76745 .0530 .0000

normal-m. dose $3.4127 \quad 2.43424 .3910 .0000$

The analysis of percentile results showed that the two studied compounds have comparable toxicological AChE inhibition effects, toxicity being higher for NIMP for the studied dosing intervals.

- The syntheses' main objective was obtaining nonvolatile chemical compounds that can be utilized as neurotoxic agents simulators: in this case, to phosphorylate cholinesterase with the same radicals as the respective neurotoxic agents, thus becoming relevant for the studying of cholinesterase reactivators. The results have confirmed that the proposed standards for the two compounds, NIMP and NEMP, were reached with a purity higher than $90 \%$.

\section{Simulator compound NIMP:}

- has a DL 50 of $0.45 \pm 0,002 \mathrm{mg} / \mathrm{kg}$ i.p in the interval of $0.32-0.59 \mathrm{mg} / \mathrm{kg}$ i.p.

- administering three doses in logarhythmic progression in the above interval shows, dose-correlated, an effect of erythrocytary AChE inhibition of 53 to $95 \%$, values that are comparable to those determined by the reference compound.

\section{Simulator compound NEMP:}

- has a DL 50 of $0,51 \pm 0,003 \mathrm{mg} / \mathrm{kg}$ i.p in the interval of $0.4-0.64 \mathrm{mg} / \mathrm{kg}$ i.p.

- administering three doses in logarhythmic progression in the above interval shows, dose-correlated, an effect of erythrocytary AChE inhibition of 56 to $88 \%$, values that are comparable to those determined by the reference compound.

- The two studied compounds present erythrocytary AChE inhibition properties comparable to the reference substances, which qualifies them for antidotism studies

- The comparative analysis of the toxicological properties showed the fact that the acute intrinsic toxicity $\left(D_{L}\right)$ of the studied compounds is smaller than that of the analogue neurotoxic chemical agents (sarin and VX-NATO standards as references) [28, 29].

\section{Conclusions}

The syntheses' main objective was obtaining nonvolatile chemical compounds that can be utilized as neurotoxic agents simulators: in this case, to phosphorylate cholinesterase with the same radicals as the respective neurotoxic agents, thus becoming relevant for the studying of cholinesterase reactivators. The results have confirmed that the proposed standards for the two compounds, NIMP and NEMP, were reached with a purity higher than $90 \%$.

The anticholinesterase activity of these simulators of neurotoxic agents is sufficient to mimic the exposure to them, all clinical signs tipical of this intoxication being present. As is the case with acetylcholinesterase aging related to sarin and $X V$, the action of these surrogates shows a slow rate of aging, allowing for a window of therapeutic opportunity for the reactivating oximes. The potency and enzymatic aging rate induced by these simulators make them especially useful in the unfolding of antidotism studies.

Thus, we can conclude that the two studied compounds, NIMP and NEMP have AChE inhibition effects that are similar to the references and, due to their reduced intrinsic toxicity, can be adequate as simulators for antidotism studies in the laboratory.
ABBREVIATIONS: NIMP 4-nitrophenyl isopropyl methylphosphonate; NEMP 4-nitrophenyl ethyl methylphosphonate; GC-MS gas chromatography - mass spectrometry; RMN nuclear magnetic resonance; CWA/NA neurotoxic agents; AchE acetylcholinesterase; CCSMM Medical-Military Scientific Research Center; C.C.S.A.C.B.R.N.E. Scientific Research Center for CBRN Defense and Ecology

\section{References}

1. *** ATSDR: Toxic Substances Portal - Nerve Agents March, 2011.

2. BENSCHOP HP, DE JONG LP, Acc. Chem. Res., 21, 1998, p. 368.

3. PICARD B, CHATAIGNER I, MADDALUNO J, LEGROS J, Organic \& Biomolecular Chemistry, 17, 2019, p. 6528.

4. CHAMBERS HW, COBAN A, FUNCK KE, PRINGLE RB, ROSS MK, CHAMBERS JE, Toxicological Sciences, 126, no. 2, 2012, p. 525. doi: 10.1093/toxsci/kfs013.

5. GANESAN K, RAZA SK, VIJ AYARAGHAVAN R, J. Pharm. Bioall. Sci., 2, 2010, p. 166.

6. GAZI E, MITCHELL SJ , J ournal of Coatings Technology and Research, 9, 2012, p. 735.

7. HU G, XIONG W, LUO H, SHI H, LI Z, SHEN J, FANG X, XU B, ZHANG J, Appl. Spectrosc., 72, no. 1, 2018, p. 151. doi: 10.1177/ 0003702817719453.

8.*** Health and Safety Executive (2017). Chemical classification. Retrieved from http://www.hse.gov.uk/chemical-classification/

9. The Organization for the Prohibition of Chemical Weapons, http:// www.opcw.org/

10.*** Technical Secretariat of Organization for Prohibition of Chemical Weapons (1997). Convention on the Prohibition of the Development, Production, Stockpiling and use of Chemical Weapons and Destruction, Technical Secretariat of Organization for Prohibition of Chemical Weapons. Retrieved from http://www.opcw.org

11. WYKE S, BROOKE N, DOBNEY A, BAKER D, MURRAY V, Chemical Hazards and Poisons Report, 21, 2012, p. 35.

12. *** WHO (1999). WHO Public health and chemical incidents. Guidance for national regional policy makers in the public/ environmental health roles. Retrieved from International Programme on Chemical Safety, World Health Organization, Geneva.

13. *** WHO (2002). WHO Environmental health in emergencies and disasters: a practical guide. Retrieved from International Programme on Chemical Safety, World Health Organization, Geneva.

14. OHTA H, OHMORI T, SUZUKI S, IKEGAYAH, SAKURADA K, TAKATORI

T, Pharmaceutical Research, 23, no. 12, 2006, p. 2827. doi: 10.1007/ s11095-006-9123-1.

15.HUSKENS J, PRINS LJ, HAAG R, RAVOO BJ , Wiley and Sons: Hoboken, NJ, USA, 2018, ISBN 978-1-119-14346-8.

16. KIM K, TSAY OG, ATWOOD DA, CHURCHILL DG, Chem. Rev., 111, 2011, p. 5345.

17. MENDONCA, M.L., SURR, R.Q., Chemistry, 25, no. 39, 2019, p. 9217. 18. SOCEA, .LI., BARBUCEANU, S.F., ISCRULESCU, L., SOCEA, B., HRUBARU, M., PAHONTU, E.M., DIACONU, C.C., BRATU, O.G., OLARU, O.T., Rev. Chim. (Bucharest), 69, no. 12, 2018, p. 3341.

19. WIENER SW, HOFFMAN RS, J ournal of Intensive Care Medicine, 19, no. 1, 2004, p. 22.

20. KING AM, AARON CK, Emergency medicine clinics of North America, 2015, doi: 10.1016/j.emc.2014.09.010.

21. MERCEY G, VERDELET T, RENOU J, KLIACHYNA M, BAATI R, NACHON F, J EAN L, RENARD PY, Acc. Chem. Res., 45, 2012, p. 756. 22. MATAR H, GUERREIRO A, PILETSKY SA, PRICE SC, CHILCOTT RP, Toxicology, 35, 2016, p. 137.

23. PITA R, DOMINGO J, Toxics, 2, no. 3, 2014, p. 391. doi: 10.3390/ toxics2030391.

24. PUGLISI R, PAPPALARDO A, GULINO A, TRUSSO SFRAZZETTO G, Chem. Commun., 54, 2018, p. 11156.

25. ROMANO JA, LUKEY BJ, SALEM H, 2nd ed.; Taylor \& Francis Group: Oxfordshire, UK, 2007.

26. STONE R, Science, 359, no. 6371, 2018, p. 23.

27. COBAN A, CARR RL, HOWARD WC, WILLEFORD KO, CHAMBERS

JE, Toxicology letters, 248, 2016, p. 39.

28. *** Standard NATO, AEP-52, vol. I, II.

29. *** Standard NATO, AMedP-7.1.

Manuscript received: 28.10 .2019

http://www.revistadechimie.ro 